\title{
Ingroups and Outgroups in Complaints: Exploring Politic Behaviour in Nurses' Discourse
}

\author{
Ingroups y Outgroups en Quejas: Explorando el Comportamiento Político \\ en el Discurso de las Enfermeras
}

Recibido: Diciembre 2016 Aceptado: Julio 2017 Publicado: Noviembre 2017

\author{
Mariana Virginia Lazzaro-Salazar \\ Universidad Católica del Maule \\ Chile \\ mlazzaro@ucm.cl
}

\begin{abstract}
The relevance of social norms for understanding appropriate behaviour in context has taken central stage in (im)politeness research in recent years, and particularly in studies of workplace interaction (Holmes, 2012). As an example of this research, this paper explores the way in which a group of nurses interacting with their colleagues negotiates complaints. The data were collected in a ward of a public healthcare institution in New Zealand and consist of audio and video recordings of four roster meetings involving nurses and nurse managers. Instances of nurses' complaints are explored from an interactional sociolinguistic point of view, allowing the researcher to investigate emergent facework (drawing on Locher and Watts, 2005). The findings suggest that multiple ingroup and outgroup memberships, achieved through the dynamic use of personal pronouns, enact preferred politic behaviour for both, transactional and relational goals. In addition, nurses' convergence in their display of socio-pragmatic norms governing their complaining practices suggests that this group of nurses belongs to the same workplace community. Finally, strong emphasis is placed on the role that complaining plays in the positive presentation of nurses' identities.
\end{abstract}

Keywords: Complaints - group memberships - identity - politeness theory

Citación: Lazzaro-Salazar, M. V. (2017). Ingroups and Outgroups in Complaints: Exploring Politic Behaviour in Nurses' Discourse. Logos: Revista de Lingüística, Filosofía y Literatura 27(2), 319-334. DOI 10.15443/RL2725

Dirección Postal: Carmen 684, Curico, Chile

Direccion Postal: Carmen 684, Cu
DOI. doi.org/10.15443/RL2725 
Resumen: La relevancia delas normas sociales para comprender el comportamiento apropiado en contexto ha tomado un lugar central en la investigación de la (des) cortesía en los últimos años, y particularmente en los estudios sobre el lenguaje en lugares de trabajo (Holmes, 2012). Como ejemplo de esta investigación, este trabajo explora la forma en la que un grupo de enfermeras interactúa con sus colegas al negociar quejas. Los datos se recolectaron en una guardia de una institución pública de salud en Nueva Zelanda y consisten en grabaciones de audio y video de cuatro reuniones de trabajo sobre la carga horaria laboral, en las cuales participan enfermeras y directores de enfermería. En este artículo, se exploran instancias de quejas de las enfermeras desde el punto de vista de la sociolingüística interaccional, permitiendo al investigador estudiar aspectos de cortesía emergentes (basados en Locher y Watts, 2005). Los hallazgos sugieren que las múltiples pertenencias a ingroups y outgroups, logradas mediante el uso dinámico de los pronombres personales, representan un comportamiento político preferido para alcanzar objetivos transaccionales y relacionales. Además, la convergencia en el uso de las normas socio-pragmáticas que rigen las prácticas relacionadas a las quejas de estas enfermeras sugiere que este grupo de enfermeras se identifica con la misma comunidad laboral. Por último, el estudio hace hincapié en el papel que juega la queja en la presentación positiva de identidad de las enfermeras.

Palabras claves: quejas - membresías de grupo - identidad - teoría de la cortesía

\section{Introduction}

Professional discourse in healthcare settings has received much scholarly attention from discourse analysts because it is a rich context where, as in most workplaces, "resources are produced and regulated, problems are solved, identities are played out and professional knowledge is constituted" through the use of language (Sarangi \& Roberts, 1999: 1). The contributions of a discursive analytic approach have been widely acknowledged as researchers have focused on, for instance, the communicative and interpretive processes when presenting illnesses and discussing diagnoses (Roberts \& Sarangi, 2005), the way patients present their cases (Barone, 2012), and the language of morning report (Apker \& Eggly, 2004), among others (Barbour, Gill \& Dean, 2016).

In the last few decades, increasing attention has been paid to the study of politeness in healthcare settings as it clearly plays an important role in healthcare communication and, particularly, in meetings, where caregivers manage their interpersonal workplace relations as they interact with colleagues and with their managers (Zayts \& Kang, 2009; Holmes, 2012). In this light, researchers have discussed issues around politeness and hierarchical structures in interdisciplinary discharge rounds (Graham, 2009), the negotiation of politic behaviour in an L2 prenatal genetic counselling setting (Zayts \& Kang, 2009), the role of politeness in institutional elderly care from a cross-cultural perspective (Backhaus, 2009), politeness norms as health professionals interact with patients' family members (Matsuoka \& Poole, 2015), and unwanted instances of support in cancer diagnosis (Ray \& Veluscek, 2016), among others.

In particular, and possibly due to the fact that the nursing workforce constitutes the group with 
the largest representation in the healthcare sector in most countries around the world (Zurn \& Dumont, 2008; Seccombe \& Charlesworth, 2016), research on nurses' discursive practices, and politeness strategies in particular, has played an important role in the advance of healthcare communication research (Schrauf \& Müller, 2014). In this regard, the present paper aims to advance our knowledge in this field of healthcare talk by exploring an often under-research context of nursing communication, namely, workplace meetings.

This context of workplace interaction constitutes what Goffman (1959) refers to as backstage work, i.e. those instances in which only institutional members (and not patients) are involved (Bardovi-Harlig \& Hartford, 2005). Interestingly, this constitutes one of the most common workplace activities in which nurses engage, sometimes on a daily basis (Bargiela-Chiappini \& Nickerson, 2002). Seen as an "interactional joint achievement" (Asmuß \& Svennevig, 2009: 3 ), meetings are sites where nurses work together to accomplish not only transactional goals, for instance, reporting and reviewing protocols, but also relational goals, for instance, building workplace relationships (Coupland, 2000).

In the meetings explored in this paper, an important aspect of workplace communication among nurses is complaints. As the nurses in this study attend their monthly 'roster ${ }^{1}$ ' meetings, they seize the opportunity to provide feedback on a number of timetable changes that have been implemented in their ward, which often results in complaints about the number of night shifts allocated in a row, for example. In sociolinguistic research, complaints have traditionally been framed within the categorization provided by Politeness Theory as a face-threatening speech act, and its mitigation would inevitably result in an act of politeness (Brown \& Levinson, 1987). However, as Zayts and Kang (2009: 35) reflect, in most healthcare contexts where clarity in information delivery is prioritised and confrontation is not necessarily avoided, "issues of politeness (in the sense of Brown and Levinson) take a back seat."

This paper advances our knowledge of politeness phenomena in healthcare communication by exploring the linguistic strategies used by a group of nurses to voice and respond to complaints. To this end, the study is based on the analysis of nurse-nurse interaction of four roster meetings which were audio and video recorded at a public hospital in New Zealand. This study approaches the data from a discourse analytic perspective to explore group alignments as a discursive practice that enables nurses to index and negotiate their social relations in the context of complaints. At a micro-linguistic level, this paper shows how this is achieved by, in addition to lexical choices, a contextually-sensitive dynamic use of pronouns that allows nurses to index multiple group alignments. As will be argued, such multiple group membership alignments are constructed in distinctive ways as part of the socio-interactional structure that these nurses and their managers need to relevantly and appropriately voice and respond to complaints, or, in other words, to display politic behaviour in conflictive situations. Finally, emphasis is placed on how situationally appropriate discursive behaviour enables nurses to display positive aspects of their own identity.

\section{Background}

\subsection{Complaints and politic behaviour}

In general terms, a complaint can be defined as "the expression of dissatisfaction [and/or disappointment] to an interlocutor about oneself or someone/something” (Boxer, 1995: 219). For practical purposes, the instances explored in this study correspond to direct complaints (Edwards, 2005). These are instances where the voicing of the complaint has the purpose of changing the undesirable state of affairs and to that end the complainer addresses the complainee directly. In terms of its socio-pragmatic functions, direct complaints are believed to be oriented towards the transactional goals of the interaction as speakers bring forward a problem and request for action to be taken accordingly (Holmes \& Riddiford, 2010).

Studies on workplace discourse concerned with the role and enactment of complaints have 
widely framed them as a face-threatening speech act (Brown \& Levinson, 1987; Holmes \& Riddiford, 2010). In this light, direct complaints are a socially negatively evaluated speech act because they may damage interactants' face, threatening their self-image. Interlocutors can, however, positively manage their social relations by mitigating the effect of the complaint in order to avoid relational devaluation (Cupach \& Carson, 2002). This interactional move would necessarily, according to Brown and Levinson (1987), result in 'polite' linguistic behaviour (Spencer-Oatey, 2005).

As argued by Locher and Watts (2005; Spencer-Oatey, 2000), however, this rather "absolute" approach to politeness is not sufficient to explain the complexities of interactional contexts. Thus, moving beyond Brown and Levinson's considerations of politeness, an interactional approach to politeness affords a wider range of (non-)politic behaviours (Watts, 2003) to be considered, which is defined as "socio-culturally determined behaviour directed towards the goal of establishing and/or maintaining in a state of equilibrium the personal relationships between the individuals in a social group [...] during the ongoing process of interaction" (Watts, 1989: 135). Politic behaviour then is not perceived by interactants as either polite or impolite, but merely intended to maintain personal relationships (cf. rapport-maintenance orientation in Spencer-Oatey, 2005). Very importantly, it is "merely situationally-expected practice" (Brown \& Crawford, 2009: 75); thus the appropriateness of certain (linguistic or otherwise) behaviours over others will vary according to the context of interaction since these are discursively negotiated as the interaction unfolds (Locher \& Watts, 2005; Holmes, Schnurr \& Marra, 2007).

When reflecting upon the importance of this context-sensitive aspect of politeness, Zayts and Kang (2009) explain that politic behaviour is particularly prominent in those contexts where avoidance of confrontation may not be the main concern, identifying healthcare workplaces as such a context. In healthcare contexts, they contend, interactants are more likely to be involved in the negotiation of politic verbal behaviour as their main interactional aim is transactional, i.e. the sharing of information. Nevertheless, interactants are involved in relational work to maintain positive personal relationships, which is likely to result in the enactment of politic behaviour.

This view coincides with the observations explored in this paper. In meetings where the stakes are high for its members, conflict situations can be regarded as 'natural' since attendees will most certainly bring their own interests to the fore (Lazzaro-Salazar, Holmes, Marra \& Vine, 2015). In the meetings explored here, nurses and managers met monthly to discuss issues related to their shift allocation, and short change and leave requests. Stakes in these meetings were often high as being allocated the right number and kinds of shifts often meant that nurses would, for instance, get enough sleep between shifts. As nurses discussed these issues, it was common to observe complaining behaviour as they encountered problems with the roster. Voicing their complaints clearly (or directly) then was vital to make their points understood for generating satisfactory change. In this context, politeness concerns may only play a secondary role as participants in this study seem to orient more strongly towards reproducing politic behaviour with the aim of maintaining healthy workplace relations with other nurse colleagues and their managers while, at the same time, they are able to voice their complaints in direct ways. As the analysis will show, to negotiate politic behaviour for complaining, the nurses draw heavily on group membership as indexed through pronouns as a way to negotiate politic behaviour for complaining.

\subsection{Alignments: building in-groups and out-groups}

As workers engage in workplace activities, they order their social environment into groups with whom they identify (ingroups) and those with whom they do not (outgroups) (Tajfel, 1974). Members build aspects of shared professional identity (Hogg \& Terry, 2000), such as mutually held expectations about their roles within the group, as well as intentions, attitudes and perceptions of what members should be like, and what group members can or cannot do as part of that group. These characteristics of ingroups are not static but re-considered and 
re-evaluated as the members engage in meaningful interactions with relevant others (both ingroup and outgroup members; see intergroup comparative process in Tajfel, 1974; Turner, 1975; Abram \& Hogg, 2001).

The formation of ingroups and outgroups is situational, or context-dependent, and meaningful only 'at a particular point in time' (Turner, 1975). Thus, group memberships need to be contextually relevant or appropriate and evoked in interaction according to the changing interactional goals. This allows interactants to make choices that appropriately display a positive social orientation. Logically, then, social actors claim membership to not only those groups with whom they share the same set of attitudes, values, beliefs and ways of doing things (Apker \& Eggly, 2004) but also those groups that enable them to construct a positive self-image of a targeted type of social identity (Tajfel, 1974).

This reflects the multi-layered relational complexities involved in the act of complaining in which group alignments will be explored as a vehicle used by nurses to favour positive orientations of self and other as they appropriately navigate conflict talk. Moreover, in addition to other subtler discursive strategies used to position themselves as ingroup and outgroup members, this paper shows how this is discursively achieved through a dynamic use of personal pronouns, a topic which has, to date, been scarcely explored (Meinl, 2010).

\subsection{Personal pronouns in group membership: the importance of contextual sensitivity}

Most research on the pragmatic meaning of pronouns has focused on how social positionings are marked and reinforced. Enyedy and Goldberg (2004), for instance, investigated the use of exclusive ( $I$, you, she, he, they) and inclusive (we) pronouns in classroom activities. They explain that pronouns are an interactional resource that is dynamically employed to enact fluid group memberships. These allow the teacher to construct herself as part of the classroom community when assessing classwork and as an outgroup member when giving instructions.

Interactants' choice of personal pronouns then reflects their self orientations as they display (dis)alignments with certain social groups. Speakers' choice of pronouns, as well as their social orientations, is context-sensitive as they adapt to aspects of the context to be appropriate and relevant (McKenna, 2004). As Fasulo and Zucchermaglio (2002: 1121) explain personal pronouns are "dependent on context for their (referential) meaning". Thus, interactants' subjective interpretations of contextual features, such as who is speaking, to and of whom, when, where, topic of the conversation, and (institutional) roles will guide interactants' positioning and discursive choices and their understandings of these (van Dijk, 2006). Furthermore, no two interactional contexts will be the same; the contextual features will be different from interaction to interaction and even within the same interaction. As will be explored in this paper, this calls for constant reconsideration of participants' orientation and linguistic choices, which is reflected in the dynamic, and always shifting, use of personal pronouns (Pennycock, 2010). Understanding these nurses' group alignments involves providing context-sensitive interpretations of the use of personal pronouns, which, as illustrated in the analysis, can be regarded as an aspect of appropriate behaviour and group norms.

\section{Methods}

The data for this study were collected in a ward of a major tertiary public healthcare institution in New Zealand, referred to as the hospital, in 2010 as part of a larger study (Lazzaro-Salazar, $2013^{2}$ ). This data set comprises four roster meetings which were attended by nurses (those who were on duty but available at the time of the meeting), the charge nurse manager (CNM), the associate charge nurse (ACN), and occasionally by a nurse coordinator. The CNM or the ACN chaired the meeting and, on average, ten participants attended these meetings. The nurses in these meetings came from diverse cultural backgrounds, such as the Philippines, England, India, Malaysia, China, as well as New Zealand European (Pākehā) and New Zealand Māori nurses. The meetings were held monthly and, generally speaking, the meeting agenda involved discussing 
matters related to the nurses' roster for the following month. At the time of recording, the purpose of these meetings resided in the fact that there had been changes to the nurses' roster statute and the ward managers were responsible for enforcing these changes. Thus, many of the discussions about the roster concerned the institutional regulations regarding nurses' night shift allocation and holiday leave.

The study was carried out in three phases. Phase one involved observing one roster meeting and taking ethnographic notes to gain access to the natural context in which the meetings took place (Erickson, 1986). This, in turn, helped the researcher develop a descriptive understanding of participants' social reality (see Boxer, 2002). Phase two involved collecting recordings of meetings. Following a widespread practice adopted by discourse analysts (Roberts \& Sarangi, 2005), this study uses audio and video recordings of nurses' interactions with the aim of investigating "language as it occurs in everyday interaction" (Tannen \& Wallat, 1986: 295; see "situated meaning" in Gumperz, 1982). As Fairclough and Wodak (1997) note, the use of naturally-occurring interaction is central to the understanding of organizational phenomena as language constitutes and is constituted by social practice. Phase three involved interviewing the managers of the ward in order to clarify questions that arose in the preliminary analysis of the data and to gain a deeper understanding of, for instance, ward-specific protocols and manuals, specific terminology and local practices (see 'key-informant interviews' in LeCompte and Goetz, 1982).

As in previous work by the author, the analysis was carried out within the framework of interactional sociolinguistics (IS), since, as a qualitative and interpretative approach to the study of social interaction, it is rooted on the idea "that language as it is used in social interaction is constitutive of social relationships" (Trudgill, 2003: 65) and as such is interested in how language is used to maintain, develop, change and/or contest social relationships among interactants. Moreover, the extracts presented in this paper were selected for their capacity to illustrate common discursive practices and relevant socio-pragmatic features that characterise the interactional routines of the participating nurses (Lazzaro-Salazar, 2013, 2016; see appendix for transcription conventions).

\section{Results and Discussion}

\subsection{Nurses voicing their complaints}

In this dataset, nurses frequently voiced complaints supposedly on behalf of an absent third party. In the following conversation, Susan, the nurse delegate, is explaining to Nick, the CNM, that some nurses (the girls) have complained about the number of night shifts they have to do on end. Nick responds that there are no nurses rostered five nights in a row in the following month. To this Susan replies with an explanation or additional information for her initial complaint.

\section{Extract $1^{3}$}

$\begin{array}{ll}\text { 1. Susan: } & \text { /yeah i told that's what } \backslash \backslash \text { i told um } \\ \text { 2. } & \text { those the girls } \\ \text { 3. } & \text { if five nights or six m- mornings comes up } \\ \text { 4. } & \text { just relook at the roster and } \\ \text { 5. } & \text { you know }{ }^{00} / / \text { and } \backslash \text { come and } \\ \text { 6. } & \text { see you can explain to them } / / \text { how that works } \backslash^{00} \\ \text { 7. Nick: } & \text { /yeah } \backslash \backslash / \text { that's right so an- } \backslash \backslash \\ \text { 8. } & \text { and if they ARE saying to you } \\ 9 . & \text { just explain again }\end{array}$

Susan begins the explanation of her initial complaint by positioning herself as an outsider to this group of complaining girls (line 2). Susan discursively achieves this by orienting to her role as the nurse delegate rather than as a fellow nurse within the team. This role places her in the 
powerful position of being the link between the management and the nursing staff.

It is interesting, however, to note Susan's lexical choice in constructing the outgroup. On the one hand, the phrase the girls (line 2) constructs Susan as a non-member of that group of nurses. Susan later reinforces this stance through the use of them (line 6) to refer back to the girls, with no explicit reference of herself being part of this group. On the other hand, the girls also seems to be an emotionally and positively loaded term (see considerations of 'relational turns' in Koester, 2004). Thus, although in the context of this conversation this phrase is used to display disaffiliative behaviour as Susan voices the complaint on their behalf, she may be also indexing certain closeness with the group by making this apparent familiarity relevant through her discursive choice. This could suggest that Susan may not regard the girls as an outgroup at all times; rather she may sometimes consider herself a member of this group but given the potentially face-threatening context of the current interaction she may find it more useful to distance herself from that group momentarily.

Moreover, part of constructing one's professional identity also involves how relevant others react to our display of group membership stances, that is to say, how they accept or reject our positioning in interaction (this point is further explored in section 4.2 below). In the case of this extract, Nick first uses overlapping speech to display his agreement with Susan as she explains she suggested the other nurses should talk with him about their roster concerns (lines 5-7). In this way, he accepts the identity assigned to him as a superior within this team and as a knowledgeable person when it comes to dealing with roster issues. Nick also accepts Susan's self-positioning as a non-member of the girls group in line 8 when he uses the pronoun they to make reference to the girls and later addresses Susan by the pronoun you, which further supports his construction of Susan's identity (line 8). Also, Nick aligns with Susan's identity claim as a leader within the team of nurses when he acknowledges that the other nurses approach her for consultation (line 8) and when he tells her what to explain to them in line 9.

But not all such instances of in-group construction align with the hierarchical status of the participants. In other cases, identification claims need to be actively negotiated so that interlocutors accept the speaker's stance.

\section{Extract 2}

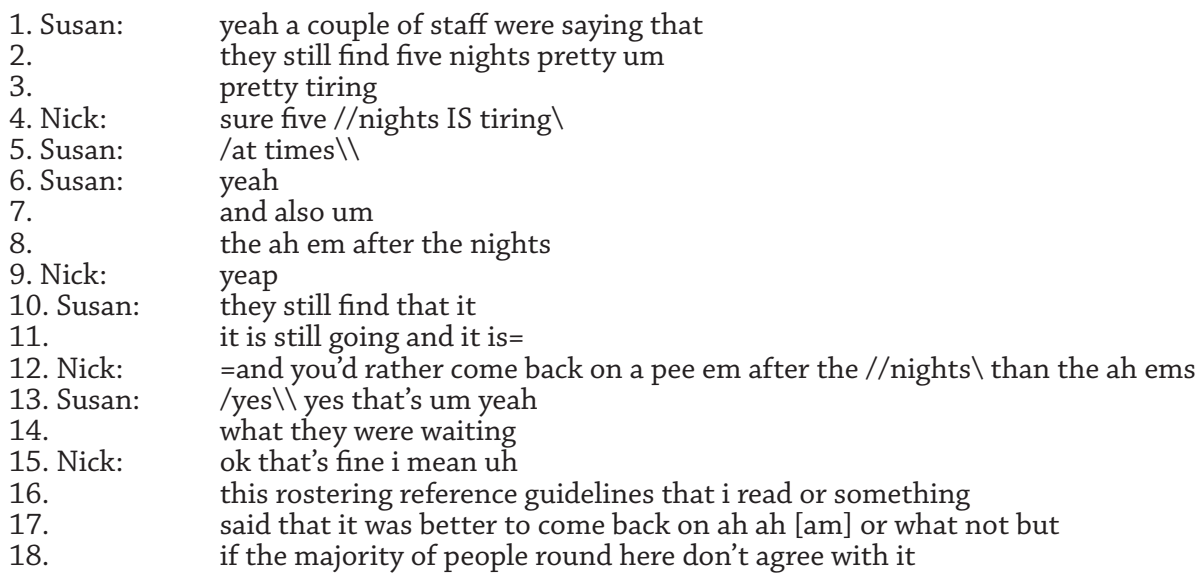

In this case, it takes Susan a number of turns to negotiate her group membership with Nick who initially rejects her construction of the other nurses as a different group. As she lodges the complaint regarding the number of nights they work in a row and the fact that sometimes nurses are assigned a morning shift after doing a night shift, Susan attributes it to the staff (line 1), this time choosing a more distancing lexical item than in the previous extract (see the girls above). This discursive choice may be based on two interrelated interactional functions: staff 
serves to create an outgroup for the current speaker which is later reinforced by the pronoun they (lines 2,10), while it could also be used to make the group to whom the complaint is attributed anonymous. In both cases, the use of the word staff may act as a face-saving strategy. Firstly, by building an outgroup Susan indexes no immediate affiliation with the group of nurses whose complaints she is voicing, which maintains her solidarity with Nick. Secondly, by using a rather generic term such as staff to refer to the team of nurses she represents, Susan is protecting the identity of the actual complainers. Though this shows that Susan is closer in hierarchy to Nick than to the girls, it also positions Susan as a collegial co-worker who realises the potential damage that a complaint could cause to her co-workers' face.

Interestingly, though Nick agrees in essence with the complaint (line 4), this time he rejects Susan's positioning as a non-member of the group of staff in line 12. The pronoun you in Nick's turn as he first addresses the complaint rejects Susan's identity claim and includes her as a member of her constructed outgroup as he rephrases the petition implied in the complaint. In the next turn, however, Susan rejects Nick's construction of her as an ingroup member and, through the use of the pronoun they, discursively negotiates her group membership orientation by restating her claim as an outsider to the staff (line 14). She succeeds in this endeavour as Nick finally accepts her identity claim in line 18 by using the phrase the majority of people. The referee in this phrase is ambiguous enough to reassert Susan's positioning and exclude her as a member of the staff group.

It is worth noting that in spite of her disaffiliative efforts, in practice, roster issues affect all the nurses, including Susan, in possibly the same ways. In this light, the interactional value of Susan's disaffiliation lies in the relational work this does for her identity and that of others at different levels of identity construction (see 'layered simultaneity' in Blommaert, 2005), all of which can potentially be perceived as positive by this team of nurses. Susan's disaffiliative behaviour allows her to do self-oriented, colleague-oriented and recipient-orientated positive relational and identity work. In terms of her own social positioning, it enables Susan to display a positive image of her professional self as a person who distances herself from actions that can give rise to workplace conflict and who favours harmonious work relationships. In addition, the use of outgroup-oriented pronouns, and some general nouns such as staff and those girls, also bears positive implications for the outgroup as they 'defocalize' the reference to the complainers (Trosborg, 1995). In this way, the identities of those nurses who complain are protected in the anonymity of pronoun usage, potentially enhancing ingroup solidarity. Moreover, such practices minimise the imposition on the recipient, which may also promote complainer-complainee solidarity (Edwards, 2005). Finally, the choice of certain group memberships discursively expressed through the use of pronouns then reflects that the strategic decisions this group of nurses employ are based on their desire to avoid conflict and to positively construct their professional identity by protecting the self-image of all participants involved.

However, as extract 3 below shows, the construction of these outgroups is temporary as Susan also claims ingroup membership to the bigger group of nurses (previously constructed as the outgroup) in other interactional contexts.

\section{Extract 3}

$\begin{array}{ll}\text { 1. Susan: } & \text { the one thing nick } \\ \text { 2. } & \text { are we allowed to do } \\ \text { 3. } & \text { only request night shifts for } \\ \text { 4. } & \text { a month } \\ \text { 5. Nick: } & \text { um } \\ \text { 6. Susan: } & \text { if we request for it }\end{array}$

In this extract, Susan raises the question of whether the nurses of this ward can request to work only nights over the period of a month. As she does this, Susan includes herself as a member of the girls group in lines 2 and 6 . She discursively achieves this through the use of the 
pronoun we, which positions her as an ingroup member. Attention needs to be drawn, however, to the fact that in this extract Susan is not voicing a complaint but requesting information (line 2). Nevertheless, the extract serves to illustrate how this change in orientation makes Susan's previous group membership orientations even more salient and marked as she discursively moves within a continuum of ingroup and outgroup construction which allows her to positively construct herself in the face of the different transactionally relevant goals in, judging by the interlocutor's responses, appropriate ways. This is further developed in what follows.

\subsection{Responding to complaints}

Complaints have often been investigated as an adjacency pair (Drew \& Walker, 2009). Thus, it is expected that when a speaker voices a complaint (initial action), the recipient will respond to this complaint in one of a number of ways available to them (paired action). Responding to complaints has pragmatic significance; in the case of this study, the way the recipient addresses the complaint displays their acceptance or rejection of the speaker's membership claims as well as the affiliative or disaffiliative stance of the recipient towards the complainer (see extracts 1 and 2).

Dealing with complaints is not an easy task for managers as they often struggle to maintain good relations with their team while communicating their decisions on a number of matters. As Holmes, Schnurr and Marra (2007: 435) explain "leadership can be productively viewed as a discursive performance in which an effective leader successfully integrates the achievement of transactional objectives with more relational aspects of workplace interaction." Eve, the NM, achieves this balance by constantly redefining her group memberships also through the skilful use of personal pronouns, as the next extract illustrates.

\section{Extract 4}

1. Eve: $\quad$ i realise you know

$2 . \quad$ that doing roster rotating shifts isn't always

3. um easy on your life so

4. you know i'm happy

5. but i'm i'm happy to work with you to make it

6. $\quad$ you know to make it work for you

7. but if we run into problems like that

8. then i'll just have to say then we'll go strictly by the book

9. $\quad$ and not allow them

10. at the minute you know

11. we're lenient on it

Eve appears to be concentrating her efforts on achieving two interrelated interactional goals, one transactional and one relational: putting an end to the problems posed by short changes (lines 7-10) and promoting, in spite of the potentially tense situation, harmonious work relations (lines 1-6). Eve blends these two aims by using multiple self and other group identifications to formulate her response to the nurses' complaint. Eve's acknowledgement of the nature of the complaint and her willingness to work with the nurses to solve this problem (lines 4-6) unequivocally positions her as the manager of the group by clearly distinguishing herself ( $I$, lines 1, 4 and 5) from the team of nurses (you, lines 5 and 6) (see disaffiliative response as 'dispreferred' in Drew \& Walker, 2009). Though the $I$ - you ingroup-outgroup construction could be said to index a disaffiliative stance on Eve's part, the general message underlying the first 6 lines seems to be a positive one as her willingness to solve the problem as a team prevails.

In line 7, however, Eve adopts a much stronger position as she warns nurses of the dangers of short changes (lines 8-9). The pronoun use in line 7 indicates that Eve's stance shifts from an exclusive $I$ (individual identity) in lines 1-6 to an inclusive we including the nurses and Eve (collective identity). This group identification is possibly employed in an effort to mitigate the seriousness of her reflection. Thus, while Eve airs some of the thorny issues concerning the 
month's roster, she manages and avoids the potential conflict resulting from this by building an ingroup that shows consideration for the nurses as they are not explicitly mentioned in the context of problematic talk (Spencer-Oatey, 2000). This team-building stance, however, quickly changes as she again resorts to leader identity demarcation when the time comes to make managerial decisions (see $I$ in line 8). Interestingly, the subject of the embedded clause in line 8 is we, which could index the same collective group membership as in line 7 and which may indicate that this decision applies to all as a team (as is the case with the conflict expressed in line 7). The fact, however, that we in line 8 is also the subject of the next coordinated sentence in line 9 raises doubts in regards to whether this we actually includes Eve and the nurses as one ingroup. In this light, we can most likely be said to exclude the nurses and to refer to a new ingroup involving Eve and Nick. This interpretation is supported by Eve's use of we in line 11, which seems to more clearly represent the management team, Nick and Eve, (see co-leadership in Vine, Holmes, Marra, Pfeifer \& Jackson, 2008), who are the only ones in this ward with the capacity to be lenient on management issues. In this case, then, we is actually excluding (rather than including, as often argued, see Enyedy and Goldberg, 2004) Eve's interlocutors while she indexes a group affiliation with members who are not present. For transactional purposes, such instances of the collective pronoun we seem to legitimise Eve's decisions by showing how these are also supported by a non-present other (Nick), which strengthens her argument and reestablishes her authority in the matter (Larson \& Pepper, 2003).

As the analysis shows, we is used in dynamic ways as a resource to display different levels of collective identity, taking on different indexical values according to the interactional demands of the discussion. The two group memberships resulting from this discursive practice construct Eve as an ingroup member with the nurses, and as ingroup member of the management team. This has significant relational implications as we is instrumentally used to fulfil the interpersonal purpose of enhancing the sense of belonging of the nurses with the ultimate goal of shaping their behaviour in a positively valued way (Larson \& Pepper, 2003). In this light, it could be argued that we is employed by Eve as a mitigating strategy when she evaluates the situation (line 7) and shares her decisions regarding the continuation of short changes (lines 8-9). It then follows that the team building capacity of this dynamic use of we has the potential to smooth out potential tensions between the manager and the nurses.

Similarly to Susan above, then, Eve includes herself in or excludes herself from the team of nurses that she leads, as she juxtaposes solidarity and support with authority in reacting to nurses' complaints. This gives Eve room to positively build her identity affiliations and that of the other nurses in dynamic ways, helping her to manage competing targets while reinforcing preferred group memberships (Larson \& Pepper, 2003). Eve then navigates the leader-member binary by appropriately indexing multiple group memberships as a way of retaining her institutional power as she also seems to be working to maintain good relations with the nurses in the context of complaints.

As the analysis shows, this multiplicity of organizational memberships seems to always be available to these nurses and managers, which provide such interactional flexibility that "an employee can be an ingroup member on one dimension and outgroup member on another" (Grice, Galloise, Jones, Paulsen \& Callan, 2006: 334; consider Susan's shifting identity orientations). Retaining the idea that "we are a bundle of identities which are brought into play through social action" (Giddens, 1991, in Allsop \& Mulcahy, 1998: 809), the interactional context of complaints requires nurses and their managers to frequently 'recycle' their memberships as they re-evaluate their stances to meet the interactional demands of the conversation with the aim of maintaining social equilibrium (see 'social mobility' in Tajfel, 1974; also see Abrams \& Hogg, 2001).

\subsection{Dynamic construction of group memberships and politic behaviour in complaints}

Such dynamic construction of group memberships seems to be a core aspect of these nurses' and managers' repertoire of linguistic strategies used to manage complaints since the majority 
of the instances of ingroup and outgroup construction recorded in this study show how functional group memberships are built through a similar use of pronouns in characteristically similar interactional contexts and for seemingly the same purposes. This suggests that these interactional practices, together with the norms that govern them, are likely to be shared by all, or most, interactants. Indeed, the extracts chosen for this paper are illustrative of what was found to occur throughout the data, which suggests that the discursive features explored are deeply ingrained or ritualised practices of this community.

In support of this, it is worth noting that nurses and nurse managers use pronouns without immediate referents and that interlocutors are able to mirror pronoun usage and contribute in relevant and appropriate ways to the conversation without asking for the clarification of these referents. Following the premise that ingroup members share their way of behaving (Bucholtz \& Hall, 2005), it can be argued that this group of nurses do in fact belong to the same ingroup or community. Moreover, judging by the interlocutors' responses, the way nurses in this study complain and respond to complaints does not seem to be perceived as either polite or impolite, but rather as "merely situationally-expected practice" that may be intended to maintain relationships among interactants in a state of equilibrium (Brown \& Crawford, 2009: 75; Psathas, 1999). It is then logical to assume that these 'ordinary' discursive practices constitute what Locher and Watts (2005) define as 'politic', that is to say, a kind of social behaviour that is unmarked and appropriate for a given situation.

As an integral aspect of normative expectations, the distinctive use of pronouns is part of the socio-interactional structure that these nurses and managers need to relevantly and appropriately voice and respond to complaints. The display of their social stance (their affiliations and disaffiliations) counterbalances the effects of a complaint in an effort to avoid conflict while conforming to their politic norms of behaviour as legitimate members of this community.

\section{Conclusions}

A fundamental consideration that stems from this study is the construction of multiple group memberships as instrumental to the management of conflict talk that may index politic, and, thus, appropriate behaviour in a team of nurses that orients towards maintaining positive interpersonal relations. As nurses voice their complaints in an effort to solve problems concerning the allocation of shifts and the request of short changes and leave, and as managers respond to these complaints, they all run the risk of engaging in face-threatening behaviour that may cause both the speaker and the interlocutor to lose face either when they complain or when they communicate their decisions. Thus, for the sake of interactional and relational harmony, it becomes important that nurses and managers deal with complaints in a way that avoids offending the interlocutor while, at the same time, they achieve the transactional goal of lodging or responding to a complaint. In this regard, this paper has shown that the dynamic construction of ingroups and outgroups through participants' choice of vocabulary and personal pronouns plays a crucial role as an indexical resource strategically employed in the discursive construction of self and others' identity orientations in appropriate ways.

\section{References}

Abrams, D. \& Hogg, M. (2001). Collective identity: Group membership and self conception. In M. Hogg \& S. Tindale (Eds.), Blackwell handbook of social psychology: Group processes (pp. 425460). Oxford: Blackwell.

Allsop, J. \& Mulcahy, L. (1998). Maintaining professional identity: doctors' responses to complaints. Sociology of Health \& Illness 20(6), 802-824. DOI: 10.1111/1467-9566.00130

Apker, J. \& Eggly, S. (2004). Communicating professional identity in medical socialization: 
Considering the ideological discourse of morning report. Qualitative Health Research 14(3), 411429. DOI: $10.1177 / 1049732303260577$

Asmuss, B., \& Svennevig, J. (2009). Meeting Talk An Introduction. Journal of Business Communication 46(1), 3-22. DOI: 10.1177/0021943608326761

Backhaus. (2009). Politeness in institutional elderly care in Japan: A cross-cultural comparison. Journal of Politeness Research. Language, Behaviour, Culture 5(1), 53-71. DOI: 10.1515/ JPLR.2009.004

Barbour, J. B., Gill, R., \& Dean, M. (2016). Work space, gendered occupations, and the organization of health: Redesigning emergency department communication. In T. Harrison \& E. Williams (Eds.), Organizations, communication, and health (pp. 101-118). New York, NY: Routledge.

Bardovi-Harlig, K. \& Hartford, B. (eds.) (2005). Interlanguage pragmatics: Exploring institutional talk. New Jersey: Lawrence Erlbaum.

Bargiela-Chiappini, F. \& Nickerson, C. (2002). Business discourse: Old debates, new horizons. International Review of Applied Linguistics in Language Teaching 40(4), 273-286. DOI: 10.1515/ iral.2002.013

Barone, S. (2012). Seeking narrative coherence: Doctors' elicitations and patients' narratives in medical encounters. PhD Thesis, Victoria University of Wellington, Wellington, New Zealand.

Blommaert, J. (2005). Discourse: A critical introduction. Cambridge: Cambridge University Press.

Boxer, D. (1995). The ethnographic interview as a tool for speech act research: The case of complaints. http://cpd1.ufmt.br/meel/arquivos/artigos/184.pdf (consulted in November 2016).

Boxer, D. (2002). Applying sociolinguistics: Domains and face-to-face interaction (Vol.15). Amsterdam: John Benjamins.

Brown, B. \& Crawford, P. (2009). Politeness strategies in question formulation in a UK telephone advisory service. Journal of Politeness Research. Language, Behaviour, Culture 5(1), 73-91. DOI: 10.1515/JPLR.2009.005

Brown, P. \& Levinson, S. (1987). Politeness: Some universals in language usage (Vol. 4). Cambridge: Cambridge University Press.

Buchan, J., Seccombe, I., \& Charlesworth, A. (2016). Staffing matters; funding counts Workforce profile and trends in the English NHS. Available in: file:///E:/Publications/WORKING/Ingroups\%20and\%20out-groups/StaffingMattersFundingCounts.pdf (consulted in November 2016)

Bucholtz, M. \& Hall, K. (2005). Identity and interaction: A sociocultural linguistic approach. Discourse Studies 7(4-5), 585-614. DOI: 10.1177/1461445605054407

Coupland, J. (Ed.). (2000). Small talk. Harlow: Longman.

Cupach, W. \& Carson, C. (2002). Characteristics and consequences of interpersonal complaints associated with perceived face threat. Journal of Social and Personal Relationships 19(4), 443-462. DOI: 10.1177/0265407502019004047

Drew, P. \& Walker, T. (2009). Going too far: Complaining, escalating and disaffiliation. Journal 
of Pragmatics 41(12), 2400-2414. DOI:10.1016/j.pragma.2008.09.046

Edwards, D. (2005). Moaning, whinging and laughing: The subjective side of complaints. Discourse Studies 7(1), 5-29. DOI: 10.1177/1461445605048765

Enyedy, N. \& Goldberg, J. (2004). Inquiry in interaction: How local adaptations of curricula shape classroom communities. Journal of Research in Science Teaching 41(9), 905-935. DOI: 10.1002/tea.20031

Erickson, F. (1986). Qualitative methods on research on teaching. In M. Wittrock (Ed.), Handbook of research on teaching (pp. 119-161). New York: Macmillan.

Fairclough, N. \& Wodak, R. (1997). Critical discourse analysis. In T. van Dijk (Ed.), Introduction to Discourse Analysis (pp. 258-284). London: Sage Publications.

Fasulo, A. \& Zucchermaglio, C. (2002). My selves and I: Identity markers in work meeting talk. Journal of Pragmatics 34(9), 1119-1144. DOI: 10.1016/S0378-2166(01)00051-0

Goffman, E. (1959). The presentation of self in everyday life. Harmondsworth: Penguin.

Graham, S. (2009). Hospitalk: Politeness and hierarchical structures in interdisciplinary discharge rounds. Journal of Politeness Research. Language, Behaviour, Culture 5(1), 11-31. DOI: 10.1515/JPLR.2009.002

Grice, T., Gallois, C., Jones, E., Paulsen, N. \& Callan, V. (2006). We Do It, but They Don't: Multiple Categorizations and Work Team Communication. Journal of Applied Communication Research 34(4), 331-348. DOI: 10.1080/00909880600908591

Gumperz, J. (1982). Discourse strategies. Cambridge: Cambridge University Press.

Hogg, M. \& Terry, D. (2000). Social Identity and Self-Categorization Processes in Organizational Contexts. Academy of Management Review 25(1), 121-140. DOI:10.5465/AMR.2000.2791606

Holmes, J. (2012). Politeness in Intercultural Discourse and Communication. In C. Bratt Paulston, S. Kiesling \& E. Rangel (Eds.), The Handbook of Intercultural Discourse and Communication (pp. 205-228). UK: Wiley Blackwell.

Holmes, J. \& Riddiford, N. (2010). Professional and personal identity at work: achieving a synthesis through intercultural workplace talk. Journal of Intercultural Communication (22).

Holmes, J., Schnurr, S. \& Marra, M. (2007). Leadership and communication: discursive evidence of a workplace culture change. Discourse \& Communication 1(4), 433-451. DOI: $10.1177 / 1750481307082207$

Koester, A. (2004). Relational sequences in workplace genres. Journal of Pragmatics 36(8), 14051428. DOI: 10.1016/j.pragma.2004.01.003

Larson, G. \& Pepper, G. (2003). Strategies For Managing Multiple Organizational Identifications A Case of Competing Identities. Management Communication Quarterly 16(4), 528-557. DOI: $10.1177 / 0893318903251626$

Lazzaro-Salazar, M. (2013). Investigating nurses' professional identity construction in two health settings in New Zealand. PhD Thesis, Victoria University of Wellington, Wellington, New Zealand.

Lazzaro-Salazar, M., Holmes, J., Marra, M. \& Vine, B. (2015). Doing power and negotiating 
through disagreement in public meetings. Journal of Pragmatics and Society 6(3), 444-464. DOI: 10.1075/ps.6.3.06laz

Lazzaro-Salazar, M. (2016). Downscaling culture in intercultural communication: The case of nurses' professional values in New Zealand. En D. Cserző, A. Kantara \& J. Singh (Eds.), The journey is its own reward: Downscaling culture in Intercultural Communication Research (pp. 114140). Cambridge: Cambridge University Press.

LeCompte, M. \& Goetz, J. (1982). Problems of reliability and validity in ethnographic research. Review of Educational Research 52(1), 31-60. DOI: 10.3102/00346543052001031

Locher, M. \& Watts, R. (2005). Politeness theory and relational work. Journal of Politeness Research 1(1), 9-33. DOI: 10.1515/jplr.2005.1.1.9

Matsuoka, R., \& Poole, G. (2015). Politeness Strategies in Healthcare Communication at" Difficult Times": A Pragmatic Analysis of the" Manga" Discourse in" Nurse Aoi". Journal of PanPacific Association of Applied Linguistics 19(2), 89-109.

McKenna, S. (2004). The intersection between academic literacies and student identities. South African Journal of Higher Education 18(3), 269-280.

Meinl, M. (2010). Electronic Complaints: An Empirical Study on British English and German Complaints on eBay. PhD Thesis, Universitäts-und Landesbibliothek Bonn.

Pennycook, A. (2010). Language as a local practice. London: Routledge.

Psathas, G. (1999). Studying the organization in action: Membership categorization and interaction analysis. Human Studies 22(2), 139-162. DOI: 10.1023/A:1005422932589

Ray, C. D., \& Veluscek, A. M. (2016). Face threats and additional reasons for perceiving support as unwanted: A study of recently diagnosed cancer patients. Health Communication, 1-7. DOI: 10.1080/10410236.2016.1228027

Roberts, C. \& Sarangi, S. (2005). Theme-oriented discourse analysis of medical encounters. Medical Education 39(6), 632-640. DOI: 10.1111/j.1365-2929.2005.02171.x

Sarangi, S. \& Roberts, C. (Eds.) (1999). Talk, work and institutional order: Discourse in medical, mediation and management settings (Vol. 1). Berlin: De Gruyter Mouton.

Schnurr, S., Marra, M. \& Holmes, J. (2007). Being (im)polite in New Zealand workplaces: Māori and Pākehā leaders. Journal of Pragmatics 39(4), 712-729. DOI: 10.1016/j.pragma.2006.11.016

Schrauf, R. W., \& Müller, N. (2014). Dialogue and dementia: cognitive and communicative resources for engagement. In R. Schrauf \& N. Müller (Eds.), Dialogue and Dementia (pp. 121146). New York: Psychology Press.

Spencer-Oatey, H. (Ed.) (2000). Culturally Speaking. Managing Rapport through Talk across Cultures. London: Continuum.

Spencer-Oatey, H. (2005). (Im)politeness, face, and perceptions of rapport: Unpackaging their bases and interrelationships. Journal of Politeness Research 1(1), 95-119. DOI: 10.1515/ jplr.2005.1.1.95

Tajfel, H. (1974). Social identity and intergroup behaviour. Social Science Information 13(2), 6593. DOI: $10.1177 / 053901847401300204$ 
Tannen, D. \& Wallat, C. (1986). Medical professionals and parents: A linguistic analysis of communication across contexts. Language in Society 15(03), 295-311. DOI: 10.1017/ S0047404500011787

Trosborg, A. (1995). Interlanguage pragmatics: Requests, complaints, and apologies (Vol. 7). Berlin: De Gruyter Mouton.

Trudgill, P. (2003). A glossary of sociolinguistics. Oxford: Oxford University Press.

Turner, J. (1975). Social comparison and social identity: Some prospects for intergroup behaviour. European Journal of Social Psychology 5, 5-34. DOI: 10.1002/ejsp.2420050102

van Dijk, T. (2006). Discourse, context and cognition. Discourse Studies 8(1), 159-177. DOI: $10.1177 / 1461445606059565$

Vine, B., Holmes, J., Marra, M.,Pfeifer, D. \&Jackson,B.(2008).Exploringco-leadershiptalkthrough interactional sociolinguistics. Leadership 4(3), 339-360. DOI: 10.1177/1742715008092389

Watts, R. (1989). Relevance and relational work: linguistic politeness as politic behavior. Multilingua 8(2), 3-131. DOI: 10.1515/mult.1989.8.2-3.131

Watts, R. (2003). Politeness. Cambridge: Cambridge University Press.

Zayts, O. \& Kang, A. (2009). “So, what test do you prefer?" Negotiating politic behaviour in an L2 prenatal genetic counselling setting in Hong Kong. Journal of Politeness Research. Language, Behaviour, Culture 5(1), 33-51. DOI: 10.1515/JPLR.2009.003

Zurn, P. \& Dumont, J. (2008). Health Workforce and International Migration: Can New Zealand Compete? World Health Organization: OECD Health Working Papers, 33.

\section{NOTES}

1. A kind of meeting in which nurses discuss the shifts allocated to them for the following month.

2. This research was supported by a Victoria University PhD Scholarship.

3. Note that some of the extracts presented in this paper have been explored elsewhere for different purposes (Lazzaro-Salazar, 2016).

\section{Appendix - Transcriptions conventions}

ME Capital letters to indicate emphatic stress

[laughter] Paralinguistic features and clarifications in square brackets

$=\quad$ Continuing speech / latching

$/ / / \backslash \quad$ Simultaneous speech

$\quad \quad$ Incomplete or cut-off utterance

${ }^{\circ} \mathrm{me}$ Two degree marks indicate increased volume of materials between them 